\title{
EXISTE IGUALDADE RACIAL NA TERRA DA LUZ?
}

\author{
Daniel Cirilo Suliano ${ }^{1}$ \\ Vitor Hugo Miro ${ }^{2}$
}

\section{Resumo}

O estado do Ceará recebeu a alcunha de "Terra da Luz" por ser a primeira província brasileira no século XIX a abolir a escravidão. Ao fazer uso dessa iniciativa pioneira o presente trabalho procurou analisar se, atualmente, o Ceará é modelo de igualdade racial para o país no âmbito das estruturas produtivas. Nesse contexto, ao utilizar-se do arcabouço econômico foram mensurados os diferenciais de salários relacionados à cor e gênero em termos de atributos produtivos e discriminatórios. Além disso, uma nova medida de capital humano foi proposta assim como três medidas proxies para a variável experiência já que as bases de dados nas pesquisas domiciliares do país presentes até então não computam uma pergunta específica para ela. Os períodos escolhidos apresentaram cenários macroeconômicos estáveis excluindo a possibilidade de serem afetados por quaisquer eventos exógenos. Os resultados encontrados demonstram que o Ceará ainda precisa percorrer um extenso caminho nos moldes de uma igualdade racial, não obstante os avanços recentes em decorrência do acúmulo de capital humano. Mesmo na "Terra da Luz", existe também um preço associado à cor.

Palavras Chave: Sociedade Cearense; Discriminação Racial; Capital Humano.

\begin{abstract}
The state of Ceara received the name "Terra da Luz" for being the first Brazilian province in the nineteenth century to abolish slavery. By making use of this pioneering initiative the present study to examine whether the state is currently a model for racial equality to Brazil. In this context, to be used in the economic framework wage differentials related to color and gender in terms of productive and discriminatory attributes were measured. Moreover, a new measure of human capital has been proposed as well as three proxies for the experience variable measures since the databases in the country household surveys not compute a specific question for her. The periods chosen has stable macroeconomic scenarios excluding the possibility of being affected by any exogenous events. The results show that the state of Ceara has yet to go a long way in the mold of a racial equality. Even in the "Terra da Luz" there is a price associated with the skin color.
\end{abstract}

Keywords: Ceara Society; Racial Discrimination; Human Capital.

\footnotetext{
${ }^{1}$ Analista de Políticas Públicas do Instituto de Pesquisa e Estratégia Econômica do Ceará. Doutor em Economia (CAEN/UFC). E-mail: daniel.suliano@ipece.ce.gov.br

${ }^{2}$ Professor da Universidade Federal do Ceará. Analista de Políticas Públicas do Instituto de Pesquisa e Estratégia Econômica do Ceará. Doutorando em Economia (CAEN/UFC).. E-mail: vitormiro@ gmail.com
}

Recebido em: 25/01/2014

Aceito em: 10/04/2014 


\section{INTRODUÇÃO}

O Estado do Ceará ficou conhecido como "Terra da Luz" por ser a primeira província brasileira no século XIX a abolir a escravidão. Em 25 de março de 1884, quatro anos antes da promulgação da Lei Áurea, a província cearense concedia liberdade à cerca de trinta mil cativos ${ }^{3}$. Segundo consta a história, o jangadeiro Francisco José do Nascimento, mais conhecido como o "Dragão do Mar", já em 30 de agosto de 1881 bradou: "No Porto do Ceará não se embarca mais escravos".

De acordo com a historiografia, o fim antecipado da escravidão no Estado se deu partir do surgimento de várias entidades abolicionistas então encabeçadas por uma classe média emergente que fazia campanhas e angariava fundos chegando algumas delas a promover e ajudar a fuga de cativos. Para o historiador Filgueira Sampaio, "o negro no Ceará era um íntimo de casa, um ente e amigo da família a quem servia com humildade e sem constrangimento".

Por outro lado, historiadores argumentam que a população escrava cearense sempre teve um papel não representativo. De fato, a estrutura produtiva local não era absorvedora de mão-de-obra desse tipo tendo em conta que predominava atividades ligadas à pecuária e cotonicultura. Nesse aspecto, a criação de gado era um tanto que imprópria para tal serviço, devido principalmente à facilidade de fugas. Para Farias (1997), essa seria a principal causa para o pioneirismo do Ceará na abolição da escravidão.

Neste trabalho, não se pretende, nem mesmo de longe, abordar as questões abolicionistas no Brasil ou mesmo adentrar nas causas que levaram o Estado do Ceará a ser o pioneiro na abolição da escravatura no país. De acordo com Fausto (1994), a simples libertação dos escravos não resultou em igualdade social entre as raças.

A ciência econômica, por sua vez, mesmo dentro das suas limitações, tem papel de investigar, ou pelo menos contribuir marginalmente para elucidação e esclarecimento de alguns fatos históricos. Conforme abordado no título deste trabalho, será que o Estado do Ceará, tendo recebido a alcunha de "Terra da Luz" a partir da iniciativa em abolir a escravidão no Brasil é também nos dias atuais exemplo de igualdade racial? O que os dados nos têm dizer? Através das bases de dados produzidas recentemente, foram aqui analisadas como andam as oportunidades de condições de igualdade racial no Estado que um dia já serviu de exemplo a sociedade brasileira.

\footnotetext{
${ }^{3}$ Atualmente Redenção, a cidade de Acarape é tida como o primeiro núcleo urbano a libertar aproximadamente cerca de 300 escravos em 1 de janeiro de 1883.
} 
A presente abordagem se resume a um ponto de vista estritamente econômico dentro do âmbito da discriminação. De com Crespo (2003), define-se discriminação como o fato de bens idênticos terem preços diferenciados, ou seja, dentro do lócus do mercado de trabalho trabalhadores com a mesma produtividade em um senso físico/material são tratados de formas desiguais com base em alguma característica observável (raça/etnia/cor).

Nesse contexto, os dados em análise foram divididos em quatro grupos, a saber: homens brancos, mulheres brancas, homens negros e mulheres negras. De fato, esse é um procedimento já consagrado na literatura especializada no Brasil (ver, por exemplo, Soares (2000) que serviu de referência para vários estudos posteriores). Seguindo essa mesma linha, os pardos foram adicionados aos negros por apresentarem estrutura social semelhante (Ribeiro, 2009). Essa divisão permite separar efeitos de gênero e raça captando de forma mais consistente os efeitos puramente discriminatórios. Além disso, foram excluídos da amostra os amarelos e os índios na medida em que os mesmos fogem do espoco de análise além de apresentarem baixa representatividade amostral.

O mercado de trabalho acaba sendo o melhor ambiente para a análise tendo em conta que funciona como um lócus que revela e que ao mesmo tempo age como um gerador de desigualdade. Neste último caso, os diferenciais de rendimentos se dão em decorrência das diferenças de produtividade dos trabalhadores como, por exemplo, diferenças decorrentes do acúmulo de capital humano. De fato, havendo diferenciais de produtividade trabalhadores com maior acúmulo de capital humano serão mais bem remunerados de forma que o mercado de trabalho apenas revela as desigualdades de dotação.

Deve-se ressaltar que a métrica de capital humano nas análises tradicionais se dá basicamente através da inclusão das variáveis escolaridade e experiência o que acaba limitando a abrangência da medida. Assim, no intuito de se mensurar de forma mais eficiente os fatores produtivos uma nova medida de capital humano foi analisada.

Barros, Franco e Mendonça (2007a, 2007d) atentam para o fato de que nem todos os postos de trabalho são igualmente produtivos e, portanto, para se comparar a produtividade intrínseca de dois trabalhadores é necessário comparar os desempenhos de cada um no mesmo posto de trabalho. Com efeito, existe uma relação direta entre estabilidade na ocupação e rendimentos do trabalhador de forma que maiores ganhos de aprendizagem, investimentos na formação e treinamento por parte das empresas por serem indissolúveis do trabalhador que ocupa determinada função acaba consubstanciando-se no seu grau de capital humano através do tempo de permanência no mesmo trabalho. Dentro desta ótica, apresenta-se aqui uma 
inovação em relação às pesquisas anteriores no cômputo das variáveis que formam o capital humano acrescentando a variável tempo de permanência no mesmo emprego.

Além desta introdução e das considerações finais este trabalho apresenta mais três seções. Na próxima seção será feita uma contextualização histórica dos trabalhos econômicos que abordaram o tema da discriminação. Em seguida é discutido os períodos em que se deu a análise bem como as demais métricas para a construção da nova medida de capital humano. A seção 4 descreve a base de dados e a metodologia empregada por meio de uma equação de salários minceriana. Na seção seguinte obtém-se o diferencial de salários com o uso da decomposição de Blinder-Oaxaca comparando-se a categoria base (homens brancos) com as demais.

\section{CONTEXTUALIZAÇÃO E ABORDAGEM TEÓRICA}

No espectro microeconômico os primeiros trabalhos que surgiram no Brasil foram àqueles motivados pelo surgimento das primeiras bases de dados e disponíveis pelo Instituto Brasileiro de Geografia e Estatística (IBGE). Conforme explanado por Menezes-Filho (2001) estes trabalhos abordaram a temática da desigualdade de renda, característica premente desde os tempos coloniais. Nesse contexto, Langoni (1973) é que deu origem a microeconometria no Brasil ao utilizar e desenvolver pioneiramente o uso de microdados a partir dos Censos de 1960 e 1970 e da Pesquisa Nacional por Amostra de Domicílios (PNAD), ambos do IBGE, para analisar a evolução e os determinantes da desigualdade de renda no Brasil de forma mais consistente.

A PNAD é uma fonte riquíssima em termos de dados abrangendo nos dias atuais todo o território nacional. Iniciada em 1967, a partir de 1971 a pesquisa passou a ter periodicidade anual. Nos anos em que ocorreu Censo - 1970, 1980, 1991, 2000 e 2010 - a PNAD não foi realizada. Em 1974 e 1975, anos estes que ocorreram o Estudo Nacional de Despesa Familiar, a pesquisa também não foi a campo assim como em 1994 devido a problemas orçamentários e atraso das pesquisas de 1992 e 1993.

Mas foi a partir da década de 1980 que a disponibilidade destas bases de dados permitiram o acompanhamento sistemático da evolução da desigualdade de renda, dos rendimentos do trabalho, do papel da escolaridade, dos níveis de pobreza e diversas variáveis de cunho socioeconômicas do país. Com efeito, diversos estudos como o de Barros, Henriques e Mendonça (2000) utilizaram como fonte a PNAD para analisar temas como bem- 
estar, pobreza e desigualdade de renda ao longo das décadas conforme a disponibilidade dos dados.

No âmbito do problema racial, Silva (1980a) é que inicia o debate refutando as teses sociológicas existentes até então no Brasil e colocando em foco o problema da discriminação ${ }^{4}$. Fazendo-se uso de uma sub-amostra de 1,27\% do Censo brasileiro de 1960 o autor aborda a questão da discriminação no mercado de trabalho na área que corresponderia hoje ao Estado do Rio de Janeiro. Os resultados rejeitam o conceito de "democracia racial" existente até então no Brasil observando que os brancos parecem desfrutar vantagens substanciais no mercado de trabalho.

Castro (1980) apesar das duras críticas a abordagem de Silva (1980a) no que tange a hipótese de varáveis não incluídas na análise apresentarem efeitos significativos nos resultados obtidos afirma não ter divergências doutrinárias ou posturas teóricas distintas em relação as suas argumentações. Enquanto o primeiro autor coloca em cheque as diferenças individuais ligadas ao ambiente familiar e a diferença na qualidade do processo escolar para as diferentes de raças Silva (1980b), em uma réplica, concorda com Castro (1980) apenas enfatizando que a magnitude do efeito da discriminação é ainda mais elevada na ausência de variáveis que captem o status das famílias.

No final dos anos 1990 outros estudos envolvendo discriminação na temática raça/cor passaram a ganhar um caráter mais sistemático através do uso da PNAD. Conforme ressaltado por Cacciamali, Tatei e Rosalino (2009) agências multilaterais e mobilização dos movimentos sociais foram fundamentais para ampliação de estudos e a geração de informações sobre a questão.

É importante destacar que apenas em 1982 a PNAD reportou uma pergunta relativa a raça/cor do indivíduo retomando novamente somente em 1986. A partir de 1987 a pesquisa computou em seu questionário principal para toda a amostra uma pergunta sistemática no que se refere à auto identificação racial dos entrevistados. Dentro desse contexto, destaca-se o estudo pioneiro de Calvalieri e Fernandes (1998) ao analisar os diferenciais de salários por gênero e raça entre duas grandes regiões metropolitanas do Brasil.

Em seguida, diversos estudos usando como ponto de corte a PNAD de 1987 abordarm por diferentes óticas questões referentes à discriminação e a cor dentro do mercado de trabalho brasileiro. Soares (2000), por exemplo, aborda exaustivamente as bases de dados da PNAD de 1987 a 1998. Campante, Crespo e Leite (2004) buscam complementá-lo

\footnotetext{
${ }^{4}$ Outro estudo pioneiro é o de Carlos Hasenbalg: Discriminação e Desigualdades Raciais no Brasil. Rio de Janeiro: Graal, 1979.
} 
atentando para formação heterogênea do país ao analisar o perfil discriminatório sob o aspecto regional. Além disto, conferem uma nova roupagem nas variáveis que interferem no processo de acumulação de capital humano tendo em conta o forte mecanismo de transmissão intergeracional de educação no Brasil. A partir do suplemento referente a variáveis que envolvem a formação de capital humano do indivíduo, tais como educação do pai e da mãe, usam como fonte o suplemento da PNAD de 1996.

Matos e Machado (2006) fazem também uso da PNAD de 1987 e estendem seu horizonte de tempo até 2001. Cacciamali e Hirata (2005) exploram a PNAD de 2002 tendo como enfoque diferenças regionais na medida em que abordam os Estados da Bahia e São Paulo. Menezes, Carrera-Fernandez e Dedecca (2005) não abordando diretamente o problema da questão racial e de gênero analisam as regiões metropolitanas de São Paulo e Salvador a partir dos dados da Pesquisa de Emprego e Desemprego (PED).

Mais recentemente, e dando continuidade ao tema a partir das pesquisas domiciliares, Cacciamali, Tatei e Rosalino (2009) fazem uso dos dados da PNAD a partir de 2002 estendendo a análise até o ano de 2006 e tendo como pano de fundo a forte expansão dos programas sociais por parte das diversas esferas do governo no início do século XXI.

\section{MÉTRICAS CONSTRUÍdAS E PERÍODOS DE ANÁLISE}

Este trabalho procurará se inserir na literatura econômica dando uma contribuição marginal por diversas frontes. O primeiro e importante aspecto a ser ressaltado aqui é que conforme alguns historiadores já bem documentaram a discriminação possui origens e reflexos que vão além do campo da análise econômica por envolver razões de ordem sociais, culturais e psicológicas constituindo-se, portanto, objeto de interesse de diferentes áreas do conhecimento.

Assim, a partir de um enfoque econômico e levando-se em conta as bases de dados disponíveis foi utilizado três momentos da conjuntura econômica brasileira. Basicamente, os períodos escolhidos tiveram três características a seu favor. Em primeiro lugar, pelo menos dois deles não foram ainda abordados em nenhum dos estudos acima citados. Além disso, os três apresentaram cenários macroeconômicos estáveis excluindo, assim, a possibilidade de serem afetados por quaisquer eventos exógenos. Adicionalmente, como estão separados intertemporalmente permitem a observância da continuidade ou descontinuidade de qualquer tendência observada. 
A partir dos dados da PNAD foram escolhidos os anos de 1986, 1996 e o período 2001 a 2007 (neste último, os dados foram empilhados em forma de pooling caracterizado apenas como um período). No caso do ano de 1986 além de não ter sido explorado em trabalhos anteriores o mesmo caracterizou-se por substanciais ganhos de renda real para todos os segmentos da população economicamente ativa, principalmente os mais pobres (Bonelli e Sedlacek, 1991) ${ }^{5}$.

O ano de 1996 é de pós-estabilização monetária ao Plano Real caracterizado tanto por redução da pobreza como por aumento da renda média (Ramos e Mendonça, 2005). Além disso, da mesma forma que a PNAD de 1982 a PNAD do ano de 1996 contém um suplemento referente ao nível de instrução da mãe permitindo construir uma medida mais ampla de capital humano dos indivíduos. Já o período 2001-2007 de acordo com Barros et al. (2010) apresentou acentuada queda nos níveis de pobreza e extrema pobreza, redução na desigualdade e melhorias nas rendas não derivadas do trabalho e derivadas do trabalho (este último em conseqüência da expansão educacional ocorrida nos últimos anos). Mesmo com a disponibilidade dos dados, a eventual crise financeira internacional no ano de 2008 não acarreta um cenário compatível com os demais anos (daí a opção de não incluí-lo na amostra do pooling).

Além da inclusão da variável tempo de permanência no mesmo emprego outra novidade aqui apresentada se deu com relação à experiência do trabalhador. Dentro da literatura econômica, observa-se pelo menos três medidas proxy para a construção dessa variável já que os questionários das pesquisas domiciliares brasileiras não reportam tal pergunta diretamente ao entrevistado. Na primeira delas, segue-se a abordagem de Heckman, Tobias e Vytlacil (2000) segundo a qual a idade é subtraída dos anos de estudo e dos anos pré-escolares (experiência $=$ idade - escolaridade -6 ). Outra medida proxy apresentada aqui se dá através da subtração da idade do indivíduo pela idade em que ele começou a trabalhar ${ }^{6}$. Por fim, a própria idade é muito comumente usada como medida proxy para experiência.

\footnotetext{
${ }^{5}$ Em $1^{\circ}$ de março de 1986 foi lançado o Plano Cruzado tendo como uma de suas metas o congelamento de preços. Inicialmente, o plano foi bem sucedido na medida em que conteve a inflação e elevou o poder aquisitivo da população. No entanto, esses dois elementos combinados acabaram elevando a demanda em decorrência de um nível de consumo reprimido o que causou um desarranjo na oferta de bens e pressão no nível geral de preços. Em razão do calendário eleitoral o governo manteve até novembro os preços congelados tendo disparado logo após o pleito. Dentro desse contexto deve-se ressaltar que setembro é o mês de referência da PNAD o que caracterizaria o ano de 1986 como de relativa estabilidade macroeconômica quando comparado à hiperinflação dos anos 80 e meados de 90 .

${ }^{6}$ Resende e Wyllie (2006) usando dados da Pesquisa do Padrão de Vida (PPV) do IBGE fazem uso também dessa medida.
} 
É importante destacar que as três medidas de mensuração da experiência potencial apresentam problemas no que diz respeito à experiência efetiva das pessoas. No caso dos trabalhadores com diferentes características demográficas e distintas formas de ocupação apresentarem ocorrências de desemprego diferenciadas a proxy experiência 1 estaria superestimando as medidas efetivas de experiência. Na proxy experiência 2, a possibilidade de desemprego por parte de alguns trabalhadores também tende a superestimar a variável construída. Já na proxy experiência 3 o simples uso da idade das mulheres pode não refletir sua experiência no mercado de trabalho devido suas decisões de fecundidade e formação familiar (Leme e Wajnman, 2001). Assim, a inclusão da variável tempo de permanência no mesmo emprego seria também uma forma de dirimir o problema relativo à variável experiência ${ }^{7}$.

Usando o suplemento da PNAD de 1996, e somente para esse ano, foi construída uma medida ainda mais ampla de capital humano através do nível de escolaridade da mãe do indivíduo. Pesquisas recentes usando essa mesma base de dados mostram que o grau de mobilidade intergeracional de educação no Brasil é menor do que o observado nos países desenvolvidos e nos países em desenvolvimento para os quais existem dados disponíveis, com exceção da Colômbia. Além do mais, essa persistência intergeracional de educação no país é de maneira significativa mais elevada entre filhos de pais com baixa escolaridade que para filhos de pais com maior escolaridade (Ferreira e Veloso, 2003). Conforme argumenta Castro (1980), variáveis que captem diferenças no ambiente familiar podem dirimir a variância da renda que eventualmente se atribui à raça dos indivíduos.

\section{DESCRIÇAO DOS DADOS E MODELO ECONOMÉTRICO}

\section{1 - BASE DE DADOS}

A PNAD é uma base de dados que apresenta uma amostragem extensa e heterogênea. Neste sentido, foram feitas algumas filtragens na amostra como tentativa de captar da melhor forma possível efeitos reveladores da desigualdade através de medidas de produtividade e outras características observadas dos trabalhadores. Em primeiro lugar, optou-se por incluir somente os trabalhadores economicamente ativos com renda positiva e com idade entre 19 e 65 anos.

\footnotetext{
${ }^{7}$ Giuberti e Menezes-Filho (2005) apresentam tentativa parecida a partir da inclusão da variável número de meses no emprego atual.
} 
Em segundo lugar, foram excluídos os trabalhadores que se declararam na ocupação serem da produção para o próprio consumo e na construção para o próprio uso já que atividades deste fim apresentam características distintas das demais em termos de produtividade e fatores associados a componentes discriminatórios ${ }^{8}$.

Feita essas ressalvas, são apresentadas estatísticas descritivas a partir de um quadro comparativo entre as diferentes categorias de sexo e raça no âmbito do mercado de trabalho cearense considerando os três períodos de análise. Na Tabela 1 é feito um quadro comparativo a partir do salário/hora de cada categoria com o objetivo inicial de obter algum grau de diferenciação entre elas. O valor monetário dos salários foi deflacionado a preços constantes de 2008 através do Índice Nacional de Preços ao Consumidor (INPC) do IBGE. A opção pelo salário hora em detrimento ao salário médio mensal deve-se as diferenças de jornada de trabalho entre os sexos já que existe a possibilidade de algumas mulheres terem jornada inferior de forma que o salário medido em termos de hora possa refletir melhor aspectos produtivos ou discriminatórios.

\begin{tabular}{|c|c|c|}
\hline Categorias & Período & $\begin{array}{c}\text { Percentual em } \\
\text { relação aos } \\
\text { Homens Brancos }\end{array}$ \\
\hline \multicolumn{3}{|c|}{1986} \\
\hline \multicolumn{3}{|l|}{ Homens } \\
\hline Brancos & 12.22 & - \\
\hline \multicolumn{3}{|l|}{ Mulheres } \\
\hline Brancas & 7.88 & $65 \%$ \\
\hline \multirow{2}{*}{\multicolumn{3}{|c|}{ Mulheres }} \\
\hline & & \\
\hline Negras & $\begin{array}{l}3.53 \\
1996\end{array}$ & $29 \%$ \\
\hline \multicolumn{3}{|l|}{ Homens } \\
\hline \multicolumn{3}{|l|}{ Mulheres } \\
\hline Brancas & 5.83 & $80 \%$ \\
\hline \multicolumn{3}{|l|}{ Mulheres } \\
\hline Negras & $\begin{array}{c}3.14 \\
\text { 2001-2007 (pooling) }\end{array}$ & $43 \%$ \\
\hline \multicolumn{3}{|l|}{ Homens } \\
\hline $\begin{array}{l}\text { Brancos } \\
\text { Mulheres }\end{array}$ & 5.51 & - \\
\hline Brancas & 5.09 & $92 \%$ \\
\hline $\begin{array}{l}\text { Homens Negros } \\
\text { Mulheres }\end{array}$ & 3.51 & $64 \%$ \\
\hline Negras & 3.12 & $57 \%$ \\
\hline $\begin{array}{l}\text { Fonte: Cálculo p } \\
\text { Nota: O Teste de } \\
\text { diferença de méd } \\
\text { outras categorias }\end{array}$ & $\begin{array}{l}\text { os autores a partir dos d } \\
\text { iferença de Média mos } \\
\text { entre os homens branc }\end{array}$ & $\begin{array}{l}\text { lados da PNAD. } \\
\text { strou haver } \\
\text { cos e todas as }\end{array}$ \\
\hline
\end{tabular}

\footnotetext{
${ }^{8} \mathrm{Na}$ verdade, em ocupações desse tipo não tem sentido falar em discriminação.
} 
Pode-se observar que ao longo dos três períodos ocorre um estreitamento no que tange as diferenças salariais entre os homens brancos e as demais categorias. Além disso, essa diferença é bem menos aguçada com relação às mulheres brancas e visivelmente ampla em relação às mulheres negras. Não obstante a menor disparidade entre os grupos ao longo dos três períodos, o teste de diferença de média mostrou haver diferença estatística em todos os resultados, mesmo no período 2001-2007, quando as mulheres brancas já ganhavam $92 \%$ dos salários dos homens brancos.

Por sua vez, sendo o capital humano fator chave na determinação dos diferenciais salariais a Tabela 2 seguinte discorre para cada categoria e período analisado a média das variáveis que fazem parte de seu cômputo geral como forma de observar se tais diferenças salariais possam ser apenas resultantes dos determinantes intrínsecos da produtividade dos trabalhadores.

Tabela 2 - Composição do Capital Humano no Ceará - Médias

\begin{tabular}{|c|c|c|c|c|c|c|}
\hline Categorias & $\begin{array}{c}\text { Anos } \\
\text { de } \\
\text { Estudo }\end{array}$ & $\begin{array}{c}\text { Proxy } \\
\text { Experiência } \\
1\end{array}$ & $\begin{array}{c}\text { Proxy } \\
\text { Experiência } \\
2\end{array}$ & \begin{tabular}{|c|} 
Proxy \\
Experiência \\
3
\end{tabular} & Permanência & $\begin{array}{c}\text { Percentual } \\
\text { de mãe } \\
\text { analfabeta }\end{array}$ \\
\hline & \multicolumn{6}{|c|}{1986} \\
\hline Homens & & & & & & \\
\hline $\begin{array}{l}\text { Brancos } \\
\text { Mulheres }\end{array}$ & 4.8 & 25.9 & - & 36.7 & - & - \\
\hline Brancas & 6.3 & 21.9 & - & 34.2 & - & - \\
\hline $\begin{array}{l}\text { Homens Negros } \\
\text { Mulheres }\end{array}$ & 3.0 & 26.7 & - & 35.8 & - & - \\
\hline Negras & \multicolumn{6}{|c|}{1996} \\
\hline $\begin{array}{l}\text { Homens } \\
\text { Brancos } \\
\text { Mulheres }\end{array}$ & 6.2 & 24.3 & 22.8 & 36.5 & 8.8 & 37.1 \\
\hline Brancas & 8.2 & 20.8 & 18.5 & 35.1 & 7.2 & 26.8 \\
\hline $\begin{array}{l}\text { Homens Negros } \\
\text { Mulheres }\end{array}$ & 4.0 & 26.1 & 23.5 & 36.2 & 9.4 & 54.2 \\
\hline Negras & \multicolumn{6}{|c|}{ 2001-2007 (pooling) } \\
\hline $\begin{array}{l}\text { Homens } \\
\text { Brancos } \\
\text { Mulheres }\end{array}$ & 6.9 & 24.1 & 23.2 & 37.0 & 8.6 & - \\
\hline Brancas & 9.0 & 21.3 & 20.2 & 36.3 & 7.0 & - \\
\hline $\begin{array}{l}\text { Homens Negros } \\
\text { Mulheres }\end{array}$ & 5.4 & 25.2 & 23.5 & 36.7 & 8.7 & - \\
\hline Negras & 7.2 & 23.0 & 21.3 & 36.1 & 6.8 & - \\
\hline
\end{tabular}

Fonte: Cálculo pelos autores a partir da PNAD.

Pode-se destacar que em todos os três períodos analisados as mulheres brancas apresentam maior média de escolaridade enquanto que os homens negros são os que detêm a menor média. Essa é uma primeira observação válida: um dos atributos mais importante na formação de capital humano revela uma média superior em favor das mulheres brancas em 
relação a todas as demais categorias, inclusive a categoria de referência (homens brancos). Outro resultado interessante em termos de anos de estudos é que em 1986 as mulheres negras detinham uma média um pouco menor que os homens brancos revertendo o processo no período 2001-2007.

Em quase todas as variáveis proxy de experiência os homens apresentam valores médios ligeiramente superiores as mulheres para os três períodos analisados. No caso da primeira, construída a partir da subtração dos anos de estudos das pessoas e disponível para todos os períodos, os homens negros levam uma leve vantagem já que apresentam a menor média de escolaridade. Situação semelhante acontece no caso da segunda proxy, disponível apenas para 1996 e 2001-2007 e construída a partir da idade em que a pessoa começou a trabalhar. De fato, por talvez adentrarem mais precocemente no mercado de trabalho os homens detiveram uma leve vantagem na média dessa variável. Na proxy 3, novamente disponível para todos os três períodos, e construída somente em função da idade dos trabalhadores, as médias para os homens são novamente ligeiramente superiores, principalmente em 1986. No período 2001-2007 as diferenças nesta última medida são praticamente inexistentes.

Deve-se destacar a importância da inclusão da variável tempo de permanência no mesmo emprego refletindo as diferenças de atributos produtivos entre as categorias na medida em que os homens, brancos e negros, dominam as maiores médias. Por fim, pode-se testificar o mecanismo de transmissão intergeracional de educação no Brasil. Com efeito, mulheres brancas e homens negros, detentores respectivamente da maior e menor média de anos de estudos apresentam o menor e o maior percentual de mães analfabetas.

\section{2 - ESPECIFICAÇÃO ECONOMÉTRICA}

A decomposição da diferença entre rendimentos por grupos (gênero e raça) é uma das metodologias consagradas na análise microeconométrica conhecido na literatura como decomposição de Oaxaca-Blinder (Blinder, 1973) e (Oaxaca, 1973) na qual se desmembra a diferença de salários entre dois grupos bem definidos em pelo menos duas partes. Uma parte é explicada pelas características produtivas dos indivíduos tais como educação, experiência no mercado de trabalho, etc. A outra parte não pode ser relacionada a características produtivas e costuma ser atribuída às demais características individuais como o sexo e raça.

O método consiste em estimar equações de salários em escala logarítmica como as definidas por Mincer (1974) relacionando características e as incorporando ao modelo 
estatístico como variáveis explicativas. As equações de salários mincerianias para cada um dos grupos de gênero e raça considerados podem ser especificadas da seguinte forma:

$$
\ln w h_{g}=\alpha_{g}+\beta_{g} X_{g}^{\prime}+\varepsilon_{g}
$$

Nessa equação, $w$ é o salário real horário, $X$ um conjunto de variáveis explicativas que representam o capital humano e outras características observadas dos trabalhadores e $\boldsymbol{\varepsilon}$ um termo de erro dado por características não observadas.

O método decompõe a diferença entre o salário médio para cada um dos grupos tomando uma das categorias como referência. O diferencial de salário consiste em um procedimento que toma a diferença dos valores estimados em função de características dos indivíduos. Considerando $g=0$ para o grupo de referência, obtêm-se:

$$
\left(\ln w h_{g}-\ln w h_{0}\right)=\left(\alpha_{g}-\alpha_{0}\right)+\left(\beta_{g} X_{g}^{\prime}-\beta_{0} X_{0}^{\prime}\right)
$$

Para o salário real horário, sua construção se deu a partir da divisão do rendimento do trabalho principal por quatro tendo como produto o rendimento semanal do trabalho. A este último resultado dividiu-se pelo número de horas trabalhadas por semana obtendo-se o salário real horário a preços constantes de 2008 com base no INPC.

Quanto às características observadas, a Tabela 3 a seguir discorre em maiores detalhes tanto em relação àquelas ligadas à formação de capital humano como as demais variáveis explicativas utilizadas na estimação da equação de salários.

Tabela 3 - Descrição das Variáveis Explicativas do Modelo

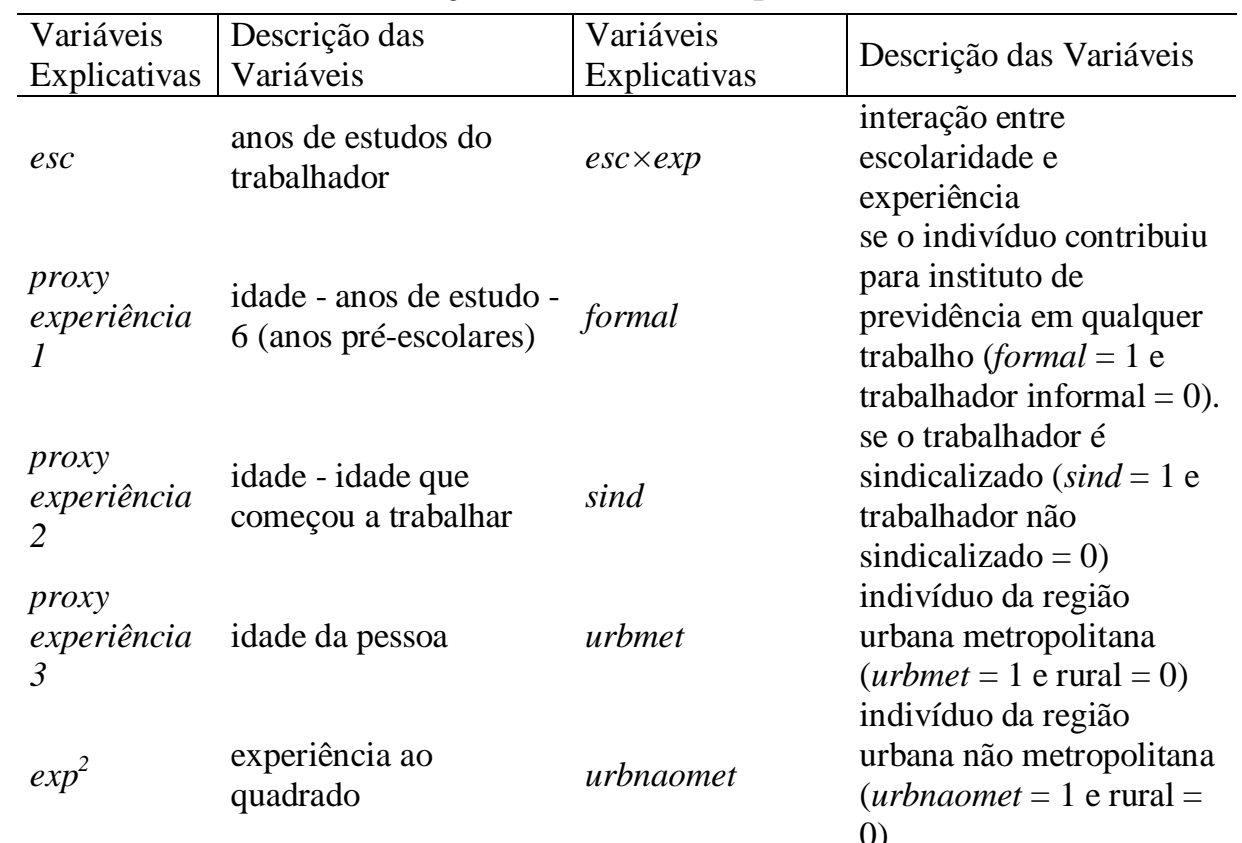




\begin{tabular}{|c|c|c|c|}
\hline maealfa & $\begin{array}{l}\text { mãe alfabetizada }=1 \text { e } \\
\text { mãe analfabeta }=0\end{array}$ & $\begin{array}{l}\text { industria, } \\
\text { serviços }\end{array}$ & $\begin{array}{c}\text { trabalhador do setor } \\
\text { industrial (industria }=1 \mathrm{e} \\
\text { agricultura }=0 \text { ) } \\
\text { trabalhador do setor } \\
\text { serviços }(\text { serviços }=1 \mathrm{e} \\
\text { agricultura }=0 \text { ) }\end{array}$ \\
\hline perm $^{2}$ & $\begin{array}{l}\text { tempo de permanência } \\
\text { do indivíduo no mesmo } \\
\text { trabalho } \\
\text { tempo de permanência } \\
\text { do indivíduo no mesmo } \\
\text { trabalho ao quadrado }\end{array}$ & chefdom & $\begin{array}{l}\text { posição na ocupação no } \\
\text { trabalho principal } \\
(\text { empregador }=1 \mathrm{e} \\
\text { demais ocupações }=0) \\
\text { chefe de domicílio } \\
(\text { chefdom }=1 \text { e demais } \\
\text { membros }=0)\end{array}$ \\
\hline
\end{tabular}

Fonte: Construção pelos autores.

A Tabela 3 apresenta um termo quadrático tanto para a variável experiência como para a variável permanência assim como uma interação entre a variável educação e experiência (ver Wooldridge, 2002). A inclusão destes controles se dá através de um coeficiente $\delta: \delta$ é a diferença no logaritmo do salário real horário considerando constante os demais controles e as características não observadas (o mesmo termo de erro $\mathcal{E}$ ). Por exemplo, se $\delta_{e s c}>0$, então, dados os controles especificados e as características não observadas, um ano a mais de estudo eleva em um montante $\delta$ o salário real do indivíduo. Em termos de efeitos parciais, assumindo a hipótese de média condicional zero para o erro, $E(\varepsilon \mid$ controles $)=0$, tem-se:

$$
\hat{\delta}_{e s c}=\frac{\partial w}{\partial x_{e s c}}
$$

Os controles são os mesmos em ambas as expectativas dando-se a diferença somente em termos da escolaridade média. Assim, o controle $i$, dado pelo nível de capital humano ou outras características observadas, eleva em um montante fixo a diferença salarial dos trabalhadores.

A partir da equação (02), o próximo passo é decompor o diferencial de salários em uma parte atribuída às características que foram listadas acima e outra atribuída à discriminação no mercado de trabalho representada por fatores não-explicados diretamente pelo modelo. Aplicando algumas transformações algébricas e reorganizando os termos obtémse a seguinte expressão:

$$
\left(\ln w h_{g}-\ln w h_{0}\right)=\left(\alpha_{g}-\alpha_{0}\right)+\left(X_{g}^{\prime}-X_{0}^{\prime}\right) \beta_{0}+X_{g}^{\prime}\left(\beta_{g}-\beta_{0}\right)
$$

Podemos assim decompor a diferença de rendimentos em dois termos. O primeiro $\left[\left(X_{g}^{\prime}-X_{0}^{\prime}\right) \beta_{0}\right]$ é atribuído às características observadas dos dois grupos também 
referenciada como "efeito dotação". Neste caso, o coeficiente $\beta_{0}$ é mantido fixo e avalia-se o diferencial em função das características observadas.

Já o segundo termo $\left[X_{g}^{\prime}\left(\beta_{g}-\beta_{0}\right)\right]$ mantém fixas as características de um determinado grupo e atribui a diferença aos coeficientes. Este componente é definido como sendo a diferenciação na forma de remunerar agentes igualmente produtivos onde coeficientes diferentes implicam em diferentes formas de remunerar as características de cada grupo sendo, portanto, em última instância, uma medida de discriminação.

\section{DECOMPOSIÇAO DO DIFERENCIAL DE RENDIMENTOS}

\section{1 - PREÂMBULO}

$\mathrm{Na}$ Tabela 4 a seguir são apresentados os resultados correspondentes ao diferencial de salários estimado de acordo com o método de Blinder-Oaxaca apenas para o ano de 1986 e, portanto, com medidas restritas para o nível de capital humano dos trabalhadores assim como estimações usando somente as medidas proxy experiência 1 e proxy experiência 3 (na PNAD de 1986 não era reportada a pergunta sobre a idade que o entrevistado começou a trabalhar). Nessa perspectiva, são reportados para cada um dos grupos de sexo/cor os diferenciais do logaritmo do salário/hora tomando como categoria base o salário dos homens brancos e separando os diferenciais em termos de características e em termos de coeficientes (que corresponderiam a efeitos discriminatórios).

Assim, o objetivo é analisar se os diferenciais salariais são decorrentes da composição do capital humano, do setor de atividade no qual os indivíduos estão empregados, seu tipo de ocupação, se a inserção no mercado é formal, se o trabalhador reside na região urbana metropolitana, urbana não metropolitana, ou até mesmo sua condição na família ou filiação sindical (para maiores detalhes da decomposição de cada variável ver Apêndice).

Os resultados demonstram que se os salários fossem determinados com base apenas nas características de cada categoria as mulheres brancas ganhariam até $16,72 \%$ a mais que os homens brancos enquanto os negros (homens e mulheres) ganhariam até 38,34\% a menos. Em termos de coeficientes, fator associado ao componente discriminatório, a situação é desfavorável as três categorias, principalmente as mulheres (brancas e negras). Com efeito, as mulheres negras (categoria mais discriminada entre as três) ganhavam 91,9\% a menos que os homens brancos no ano de 1986 tendo como base o modelo que considera a proxy experiência 
1. Para esse mesmo modelo as mulheres brancas ganhavam $63,6 \%$ a menos e os homens negros $13,5 \%$ (linha 2 da Tabela 4).

Considerando as diferenças em termos de características para as variáveis de capital humano pode-se destacar os maiores efeitos nos anos médios de estudo. De fato, se os salários fossem determinados somente em termos de anos de estudo, as mulheres brancas ganhariam até $37,04 \%$ a mais e os homens negros ganhariam até $29,31 \%$ a menos que os homens brancos. As mulheres negras ganhariam até $12,88 \%$ a menos. Para as variáveis de experiência, as magnitudes dos resultados não são substanciais, com exceção da proxy experiência 1 das mulheres brancas.

Em termos de coeficientes da variável escolaridade os resultados se mostram associados à cor. Com efeito, as mulheres brancas ganhavam até 53\% a mais que os homens brancos de mesma escolaridade enquanto os homens negros ganhavam até 11,54\% a menos. Os resultados das mulheres negras são inconclusivos e de baixa magnitude. Os coeficientes das medidas de experiência indicam novamente ausência de discriminação tanto para mulheres brancas como para mulheres negras (todos os coeficientes são positivos). Para os homens negros os efeitos são negativos e substanciais $(38,36 \%$ a menos na proxy experiência 1 e $35,73 \%$ na proxy experiência 2 ).

Tabela 4 - Decomposição da Diferença de Rendimentos - Capital Humano - 1986

\begin{tabular}{|c|c|c|c|c|c|c|}
\hline \multirow[b]{2}{*}{ Decomposição } & \multicolumn{2}{|c|}{ Mulheres Brancas } & \multicolumn{2}{|c|}{ Homens Negros } & \multicolumn{2}{|c|}{ Mulheres Negras } \\
\hline & $\begin{array}{c}\text { proxy } \\
\text { experiência } \\
1\end{array}$ & $\begin{array}{c}\text { proxy } \\
\text { experiência } \\
3\end{array}$ & $\begin{array}{c}\text { proxy } \\
\text { experiência } \\
1\end{array}$ & $\begin{array}{c}\text { proxy } \\
\text { experiência } \\
3\end{array}$ & $\begin{array}{c}\text { proxy } \\
\text { experiência } \\
1\end{array}$ & $\begin{array}{c}\text { proxy } \\
\text { experiência } \\
3\end{array}$ \\
\hline Características & 0.1672 & 0.1561 & -0.3834 & -0.3831 & -0.1815 & -0.1922 \\
\hline Coeficientes & -0.6361 & -0.6250 & -0.1352 & -0.1355 & -0.9190 & -0.9083 \\
\hline \multicolumn{7}{|c|}{ Diferenças Considerando Características } \\
\hline escolaridade & 0.3704 & 0.1476 & -0.2931 & -0.2589 & -0.1060 & -0.1288 \\
\hline proxy experiêncial & -0.2401 & - & 0.0172 & - & -0.0429 & - \\
\hline proxy experiência3 & - & -0.0258 & - & -0.0157 & - & -0.0270 \\
\hline \multicolumn{7}{|c|}{ Diferenças Considerando Coeficientes } \\
\hline escolaridade & 0.5299 & 0.4860 & -0.1154 & -0.0590 & -0.0102 & 0.0200 \\
\hline proxy experiêncial & 0.4532 & - & -0.3836 & - & 0.1266 & - \\
\hline proxy experiência2 & - & 0.7829 & - & -0.3573 & - & 0.3495 \\
\hline
\end{tabular}

Fonte: Cálculos pelos autores.

\section{2 - CAPITAL HUMANO E OUTRAS CARACTERÍSTICAS OBSERVADAS (2 PERÍODOS)}

Nesta sub-seção repetiu-se o mesmo procedimento da sub-seção anterior só que agora para o ano de 1996 e para o período 2001-2007. Em ambos os períodos, apresenta-se as estimações para as três medidas proxy de experiência além de uma medida ampla de capital 
humano (no caso de 1996, a medida é ainda mais abrangente conforme exposto na seção 2). As Tabelas 5 e 6 apresentam as decomposições dos diferenciais salariais em termos de características e coeficientes para cada categoria de raça/gênero tendo novamente como comparação os homens brancos.

Do ponto de vista temporal, o resultado alentador é que há um claro estreitamento no diferencial salarial em todas as categorias quando comparado com os homens brancos. $\mathrm{O}$ principal fator que contribui para esse efeito são as características, principalmente no caso das mulheres brancas. Todavia, mesmo nesta categoria isso não tem sido suficiente para sobrepor os efeitos dos coeficientes que são ainda elevados e são atribuídos a fatores discriminatórios.

Em 1996, se os salários fossem determinados com base apenas nas características de cada categoria as mulheres brancas ganhariam até $13,94 \%$ a mais enquanto as mulheres negras ganhariam até $35,32 \%$ a menos e os homens negros até 41,3\% a menos (ver linha 1 da Tabela 5). Em termos de coeficientes, os resultados são todos desfavoráveis as categorias em análise quando comparadas aos homens brancos, principalmente as mulheres brancas ou negras.

Por sua vez, quando se considera as características formadoras de capital humano observa-se que a educação é novamente a que mais contribui para o diferencial. Nas mulheres brancas o diferencial é de até $29,26 \%$ a favor delas enquanto nos homens negros o diferencial salarial é de até 32,13\% a menos. Nas mulheres negras o diferencial é de até 11,37\% a menos. Quando se compara as demais variáveis formadoras de capital humano com a educação os resultados para as características são de baixa magnitude.

Em termos de coeficientes, a maior parte dos resultados evidencia novamente fatores associados mais a discriminação de cor do que a discriminação de gênero. Nas variáveis formadoras de capital humano de 1996 a variável mãe alfabetizada e permanência não apresentaram resultados substanciais. Nas medidas de experiência, os resultados são relevantes. Os coeficientes das medidas de experiência indicam ausência de discriminação para mulheres brancas. Para os homens negros e mulheres negras os efeitos são substanciais (38,94\% a menos na proxy experiência $1,9,86 \%$ na proxy experiência 2 e 31,98\% na proxy experiência 3 para eles). No caso das mulheres negras, os resultados são, respectivamente, $36,68 \%, 18,42 \%$ e $54,68 \%$ a menos. 
Tabela 5 - Decomposição da Diferença de Rendimentos - Capital Humano - 1996

\begin{tabular}{|c|c|c|c|c|c|c|c|c|c|}
\hline \multirow[b]{2}{*}{ Decomposição } & \multicolumn{3}{|c|}{ Mulheres Brancas } & \multicolumn{3}{|c|}{ Homens Negros } & \multicolumn{3}{|c|}{ Mulheres Negras } \\
\hline & $\begin{array}{c}\text { proxy } \\
\text { experiência } \\
1\end{array}$ & $\begin{array}{c}\text { proxy } \\
\text { experiência } \\
2\end{array}$ & $\begin{array}{c}\text { proxy } \\
\text { experiência } \\
3\end{array}$ & $\begin{array}{c}\text { proxy } \\
\text { experiência } \\
1\end{array}$ & $\begin{array}{c}\text { proxy } \\
\text { experiência } \\
2\end{array}$ & $\begin{array}{c}\text { proxy } \\
\text { experiência } \\
3\end{array}$ & $\begin{array}{c}\text { proxy } \\
\text { experiência } \\
1\end{array}$ & $\begin{array}{c}\text { proxy } \\
\text { experiência } \\
2\end{array}$ & $\begin{array}{c}\text { proxy } \\
\text { experiência } \\
3\end{array}$ \\
\hline Caracteristicas & 0.1282 & 0.1394 & 0.1302 & -0.4130 & -0.4071 & -0.4106 & -0.3532 & -0.3364 & -0.3464 \\
\hline Coeficientes & -0.2011 & -0.2124 & -0.2031 & -0.0586 & -0.0645 & -0.0610 & -0.2700 & -0.2868 & -0.2768 \\
\hline \multicolumn{10}{|c|}{ Diferenças Considerando Características } \\
\hline escolaridade & 0.2926 & 0.2549 & 0.2230 & -0.3213 & -0.2844 & -0.2822 & -0.1117 & -0.1057 & -0.1137 \\
\hline $\begin{array}{l}\text { proxy } \\
\text { experiêncial }\end{array}$ & -0.0592 & - & - & 0.0344 & - & - & 0.0045 & - & - \\
\hline $\begin{array}{l}\text { proxy } \\
\text { experiência2 }\end{array}$ & - & -0.0327 & - & - & 0.0050 & - & - & -0.0057 & - \\
\hline $\begin{array}{l}\text { proxy } \\
\text { experiência3 }\end{array}$ & - & - & 0.0039 & - & - & -0.0053 & - & - & 0.0027 \\
\hline permanência & -0.0115 & -0.0168 & -0.0119 & -0.0068 & -0.0063 & -0.0059 & -0.0140 & -0.0190 & -0.0141 \\
\hline mãe alfabetizada & 0.0074 & 0.0064 & 0.0062 & -0.0122 & -0.0106 & -0.0103 & -0.0089 & -0.0066 & -0.0075 \\
\hline \multicolumn{10}{|c|}{ Diferenças Considerando Coeficientes } \\
\hline escolaridade & 0.0698 & 0.0417 & 0.0553 & -0.1575 & -0.1413 & -0.1331 & -0.1566 & -0.1510 & -0.1228 \\
\hline $\begin{array}{l}\text { proxy } \\
\text { experiêncial }\end{array}$ & 0.3785 & - & - & -0.3894 & - & - & -0.3668 & - & - \\
\hline $\begin{array}{l}\text { proxy } \\
\text { experiência } 2\end{array}$ & - & 0.4035 & - & - & -0.0986 & - & - & -0.1842 & - \\
\hline $\begin{array}{l}\text { proxy } \\
\text { experiência } 3\end{array}$ & - & - & 0.1960 & - & - & -0.3198 & - & - & -0.5468 \\
\hline permanência & -0.0463 & -0.0725 & -0.0431 & -0.0644 & -0.0933 & -0.0584 & -0.0720 & -0.0738 & -0.0690 \\
\hline mãe alfabetizada & -0.0652 & -0.0652 & -0.0631 & 0.0071 & 0.0011 & 0.0017 & 0.0371 & 0.0265 & 0.0316 \\
\hline
\end{tabular}

Fonte: Cálculos pelos autores.

No período 2001-2007 caso os salários fossem determinados com base apenas nas características os resultados seriam similares ao ano de 1996, mas com magnitudes diferentes tanto para mulheres brancas como para homens negros. Os resultados para as mulheres negras, antes desfavoráveis, agora se mostram inconclusivos (ver linha 1 Tabela 6). No que concerne aos coeficientes, componente associado aos fatores de discriminação, os resultados continuam desfavoráveis a todas as categorias com relação aos homens brancos e com efeitos ainda mais elevados.

As diferenças em termos de características no que tange a escolaridade favorecem novamente as mulheres brancas, desfavorecem os homens negros e tem efeitos pouco substanciais para as mulheres negras. As medidas de experiência e permanência não apresentam resultados relevantes. Nos coeficientes de escolaridade e experiência os resultados para as mulheres brancas e os homens negros ratificam os dos períodos anteriores. Para as mulheres negras foi observado em sua maior parte ausência de discriminação. 
Tabela 6 - Decomposição da Diferença de Rendimentos - Capital Humano - 2001-2007

\begin{tabular}{|c|c|c|c|c|c|c|c|c|c|}
\hline \multirow[b]{2}{*}{ Decomposição } & \multicolumn{3}{|c|}{ Mulheres Brancas } & \multicolumn{3}{|c|}{ Homens Negros } & \multicolumn{3}{|c|}{ Mulheres Negras } \\
\hline & $\begin{array}{c}\text { proxy } \\
\text { experiência } \\
1\end{array}$ & $\begin{array}{c}\text { proxy } \\
\text { experiência } \\
2\end{array}$ & $\begin{array}{c}\text { proxy } \\
\text { experiência } \\
3\end{array}$ & $\begin{array}{c}\text { proxy } \\
\text { experiência } \\
1\end{array}$ & $\begin{array}{c}\text { proxy } \\
\text { experiência } \\
2\end{array}$ & $\begin{array}{c}\text { proxy } \\
\text { experiência } \\
3\end{array}$ & $\begin{array}{c}\text { proxy } \\
\text { experiência } \\
1\end{array}$ & $\begin{array}{c}\text { proxy } \\
\text { experiência } \\
2\end{array}$ & $\begin{array}{c}\text { proxy } \\
\text { experiência } \\
3\end{array}$ \\
\hline Características & 0.2689 & 0.2346 & 0.2651 & -0.2406 & -0.2370 & -0.2392 & 0.0158 & -0.0041 & 0.0101 \\
\hline Coeficientes & -0.2903 & -0.2560 & -0.2865 & -0.0423 & -0.0458 & -0.0437 & -0.4186 & -0.3988 & -0.4129 \\
\hline \multicolumn{10}{|c|}{ Diferenças Considerando Características } \\
\hline escolaridade & 0.2525 & 0.1864 & 0.0811 & -0.1997 & -0.1366 & -0.0594 & 0.0303 & 0.0190 & 0.0090 \\
\hline $\begin{array}{l}\text { proxy } \\
\text { experiencial }\end{array}$ & -0.0521 & - & - & 0.0538 & - & - & -0.0510 & - & - \\
\hline $\begin{array}{l}\text { proxy } \\
\text { experiencia2 }\end{array}$ & - & -0.0594 & - & - & 0.0067 & - & - & -0.0300 & - \\
\hline $\begin{array}{l}\text { proxy } \\
\text { experiencia } 3\end{array}$ & - & - & -0.0171 & - & - & -0.0083 & - & - & -0.0213 \\
\hline permanência & -0.0071 & -0.0352 & -0.0276 & 0.0009 & 0.0010 & 0.0008 & -0.0344 & -0.0389 & -0.0320 \\
\hline \multicolumn{10}{|c|}{ Diferenças Considerando Coeficientes } \\
\hline escolaridade & 0.1841 & 0.3316 & 0.5940 & -0.2243 & -0.1977 & -0.1476 & 0.0366 & -0.0309 & 0.2436 \\
\hline $\begin{array}{l}\text { proxy } \\
\text { experiencial }\end{array}$ & 0.1856 & - & - & -0.2437 & - & - & 0.1092 & - & - \\
\hline $\begin{array}{l}\text { proxy } \\
\text { experiencia2 }\end{array}$ & - & 0.2009 & - & - & -0.1318 & - & - & -0.0312 & - \\
\hline $\begin{array}{l}\text { proxy } \\
\text { experiencia3 }\end{array}$ & - & - & 0.7378 & - & - & -0.0893 & - & - & 0.5829 \\
\hline permanência & -0.0026 & 0.0394 & 0.0336 & -0.0201 & -0.0302 & -0.0130 & -0.0325 & -0.0308 & -0.0276 \\
\hline
\end{tabular}

Fonte: Cálculos pelos autores.

\section{CONSIDERAÇÕES FINAIS}

O fato de o Estado do Ceará ter sido pioneiro na abolição da escravidão no Brasil há mais de um século rendeu-lhe a alcunha de "Terra da Luz". Por tal feito foi também escolhido recentemente para sediar uma universidade que busca maior integração racial.

É importante que se diga que o presente trabalho não procurou de maneira nenhuma inferir alguma causalidade entre o fato histórico mencionado e a igualdade/desigualdade de cor, mas sim somente observar se uma sociedade aparentemente tão a frente de sua época seria ainda hoje modelo para os demais entes federativos no que concerne a ausência de discriminação racial dentro das estruturas produtivas.

Como estratégia de análise foram utilizados três momentos diferentes da conjuntura econômica brasileira. Os períodos escolhidos são caracterizados por cenários macroeconômicos estáveis excluindo a possibilidade de serem afetados por quaisquer eventos exógenos. No período mais recente, as transformações econômicas e sociais ocorridas é algo até então inédito de acordo com os dados das pesquisas domiciliares. 
Além disso, foram feitas duas inovações no que concerne à medida de capital humano por meio da inclusão de uma nova variável que possa comparar mais eficientemente a produtividade intrínseca de dois trabalhadores e outra através do uso de diferentes proxies para a variável experiência já que as bases de dados presentes até então no Brasil não computam uma pergunta específica para ela. Dada à disponibilidade dos dados no período mediano foi utilizada uma medida ainda mais ampla de capital humano através do uso da escolaridade da mãe.

De um modo geral, os resultados encontrados demonstram que o Estado do Ceará ainda precisa percorrer um extenso caminho se quiser mesmo ser reconhecido como "Terra da Luz" nos moldes de uma igualdade racial.

Todavia, o período mais recente tem mostrado que as características formadoras de capital humano é um eficiente mecanismo na melhora das condições de igualdade. Por outro lado, deve-se ressaltar que a magnitude do coeficiente que mensura o efeito associado ao componente discriminatório ainda é elevado no caso das mulheres negras. Para os homens negros, os resultados mostram que o fardo é duplo, pois de além de apresentarem características desfavoráveis arcam com um custo associado à discriminação. Mesmo na “Terra da Luz”, existe também um preço associado à cor.

\section{REFERÊNCIAS BIBLIOGRÁFICAS}

BARROS, RP; HENRIQUES, R; MEDONÇA, R 2000 "Desigualdade e Pobreza no Brasil". Revista Brasileira de Ciências Sociais, v.15, n.42, p.123-142.

BARROS, RP; FRANCO, S; MEDONÇA, RA 2007a "Discriminação e Segmentação no Mercado de Trabalho e Desigualdade de Renda no Brasil". Rio de Janeiro: IPEA, (Texto para Discussão, 1.288).

BARROS, RP; FRANCO, S; MEDONÇA, RA 2007b “A Recente Queda da Desigualdade de Renda e o Acelerado Progresso Educacional Brasileiro da Última Década”. Rio de Janeiro: IPEA, (Texto para Discussão, 1.304).

BARROS, RP; FRANCO, S; MEDONÇA, RA 2007c "A Recente Queda da Desigualdade de Renda e o Acelerado Progresso Educacional Brasileiro da Última Década". In: BARROS, RP; FOGUEL, MN; ULYSSEA, G. (ORG). Desigualdade de Renda no Brasil: uma análise da queda recente. Brasília: Ipea, p.305-342.

BARROS, RP; FRANCO, S; MEDONÇA, RA 2007d "Discriminação e Segmentação no Mercado de Trabalho e Desigualdade de Renda no Brasil". In: BARROS, R. P.; FOGUEL, M. N.; ULYSSEA, G. (ORG). Desigualdade de Renda no Brasil: uma análise da queda recente. Brasília: Ipea, p.371-400. 
BARROS, RP; CARVALHO, M; FRANCO, S; MEDONÇA, R 2010 "Determinantes da Queda na Desigualdade de Renda no Brasil”. Rio de Janeiro: IPEA, (Texto para Discussão, 1.460).

BLINDER, AS 1973 "Wage Discrimination: Reduced Form and Structural Estimates", Journal of Human Resources, v.8, autumn, p.436-455.

BONELLI, R; SEDLACEK, GL 1991 “A Evolução da Distribuição de Renda entre 1983 e 1988”. In: CAMARGO, JM; GIAMBIAGI, F. (ORG). Distribuição de Renda no Brasil. Rio de Janeiro: Paz e Terra, p.47-70.

CACCIAMALI, MC; HIDRATA, GI 2005 "A Influência da Raça e do Gênero nas Oportunidades de Obtenção de Renda - Uma Análise da Discriminação em Mercados de Trabalho Distintos: Bahia e São Paulo". Estudos Econômicos, São Paulo, v.35, n.4, p.767795.

CACCIAMALI, MC; TATEI, F; ROSALINO, JW 2009 "Estreitamento dos Diferenciais de Salários e Aumento do Grau de Discriminação: Limitações da Mensuração Padrão?" Planejamento e Políticas Públicas, Brasília, v.33, n.1, p.196-222.

CALVALIERI, C; FERNANDES, R, 1998 "Diferenciais de Salários por Gênero e por Cor: Uma Comparação entre as Regiões Metropolitanas Brasileiras". Revista de Economia Política, São Paulo, v.18, n.1, p.158-175.

CAMPANTE, FR; CRESPO A; LEITE, PG 2004 "Desigualdade Salarial entre Raças no Mercado de Trabalho Urbano Brasileiro: Aspectos Regionais". Revista de Econometria, Rio de Janeiro, v.58, n.2, p.185-210.

CASTRO, CM 1980 "O Preço da Cor: Diferenciais Raciais na Distribuição de Renda no Brasil - Comentário". Pesquisa e Planejamento Econômico, Rio de Janeiro, v.10, n.3, p.10011006.

CRESPO, ARV 2003 "Desigualdade entre Raças e Gênero no Brasil: Uma Análise com Simulações Contra-Factuais”. Dissertação de Mestrado. PUC-RIO.

FARIAS, A 1997, História do Ceará, Fortaleza: Editora Tropical.

FAUSTO, B 1994, História do Brasil, São Paulo: Editora USP.

FERREIRA. SG; VELOSO, FA 2003 “Mobilidade Intergeracional de Educação no Brasil”". Pesquisa e Planejamento Econômico, Rio de Janeiro, v.33, n.3, p. 481-513.

GIUBERTI, AC; MENEZES-FILHO, N 2005 "Discriminação de Rendimentos por Gênero: Uma Comparação entre o Brasil e os Estados Unidos". Economia Aplicada, São Paulo, v.9, n.3, p. 369-383.

HECKMAN, J; TOBIAS, JL; VYTLACIL, E 2000 "Simple Estimators for Treatment Parameters in a Latent Variable Framework with an Application to Estimation the Returns to Schooling”. NBER Working Paper 7.950.

LANGONI, CG 2005, Distribuição de Renda e Desenvolvimento Econômico no Brasil, 3 Ed., Rio de Janeiro: FGV. 
LEME, SCM; WAJNMAN, S 2001 "Diferenciais de Rendimentos por Gênero". In: MENEZES-FILHO, N; LISBOA, M. Microeconomia e Sociedade no Brasil. Rio de Janeiro: EPGE-FGV, p.79-118.

MATOS, RS; MACHADO, AF 2006 "Diferencial de Rendimento por Cor e Sexo no Brasil". Econômica, Rio de Janeiro, v.8, n.1, p.5-27.

MENEZES-FILHO, NA 2001 "Educação e Desigualdade". In: MENEZES-FILHO, N.; LISBOA, M. (ORG). Microeconomia e Sociedade no Brasil. Rio de Janeiro: EPGE-FGV, p.13-50.

MENEZES, WF; CARRERA-FERNANDEZ; DEDECCA, C 2005 "Diferenciais Regionais de Rendimentos do Trabalho: Uma Análise das Regiões Metropolitanas de São Paulo e de Salvador”. Estudos Econômicos, São Paulo, v.35, n.2, p.271-296.

MINCER, J 1974 Schooling, Experience and Earning. New York: Columbia University Press.

OAXACA, R 1973 “Male-Female Wage Differentials in Urban Labor Markets”, International Economic Review, v.14, n.3, p.693-709.

RAMOS, L; MEDONÇA, R 2005 "Pobreza e Desigualdade de Renda no Brasil". In: GIAMBIAGI, F; CASTRO LB; VILLELA, A (ORG). Economia Brasileira Contemporânea (1945-2004). Rio de Janeiro: Campus.

RESENDE, M; WYLLIE, M 2006 "Retornos para Educação no Brasil: Evidências Empíricas Adicionais”. Economia Aplicada, São Paulo, v.10, n.3, p. 349-365.

RIBEIRO, CAC 2009, Desigualdade de Oportunidades no Brasil, Belo Horizonte: Argvmentvm.

SILVA, NV 1980a "O Preço da Cor: Diferenciais Raciais na Distribuição de Renda no Brasil”. Pesquisa e Planejamento Econômico, Rio de Janeiro, v.10, n.1, p.21-44.

SILVA, NV 1980b “O Preço da Cor: Diferenciais Raciais na Distribuição de Renda no Brasil - Réplica”. Pesquisa e Planejamento Econômico, Rio de Janeiro, v.10, n.3, p.1007-1012.

SAMPAIO, F História do Ceará, São Paulo: Editora do Brasil S/A.

SOARES, SSD 2000 “O Perfil da Discriminação no Mercado de Trabalho - Homens Negros, Mulheres Brancas e Mulheres Negras”. Brasília: IPEA (Texto para Discussão, 769).

SOUZA, S 1994, História do Ceará. Fortaleza: Fundação Demócrito Rocha.

WOOLDRIDGE, JM 2002, Econometric Analysis of Cross Section and Panel Data. Cambridge: The MIT Press. 


\section{APÊNDICE - DECOMPOSIÇÃO DA DIFERENÇA DE RENDIMENTOS - CARACTERÍSTICAS OBSERVADAS}

Tabela 7 - Decomposição da Diferença de Rendimentos - 1986

\begin{tabular}{|c|c|c|c|c|c|c|}
\hline \multirow[b]{2}{*}{ Decomposição } & \multicolumn{2}{|c|}{ Mulheres Brancas } & \multicolumn{2}{|c|}{ Homens Negros } & \multicolumn{2}{|c|}{ Mulheres Negras } \\
\hline & $\begin{array}{c}\text { proxy } \\
\text { experiência } \\
l\end{array}$ & $\begin{array}{c}\text { proxy } \\
\text { experiência } \\
3\end{array}$ & $\begin{array}{c}\text { proxy } \\
\text { experiência } \\
1\end{array}$ & $\begin{array}{c}\text { proxy } \\
\text { experiência } \\
3\end{array}$ & $\begin{array}{c}\text { proxy } \\
\text { experiência } \\
1\end{array}$ & $\begin{array}{c}\text { proxy } \\
\text { experiência } \\
3\end{array}$ \\
\hline Características & 0.1672 & 0.1561 & -0.3834 & -0.3831 & -0.1815 & -0.1922 \\
\hline Coeficientes & -0.6361 & -0.6250 & -0.1352 & -0.1355 & -0.9190 & -0.9083 \\
\hline \multicolumn{7}{|c|}{ Diferenças Considerando Características } \\
\hline escolaridade & 0.3704 & 0.1476 & -0.2931 & -0.2589 & -0.1060 & -0.1288 \\
\hline proxy experiêncial & -0.2401 & - & 0.0172 & - & -0.0429 & - \\
\hline proxy experiência 3 & - & -0.0258 & - & -0.0157 & - & -0.0270 \\
\hline filiação sindical & -0.0214 & -0.0212 & -0.0108 & -0.0107 & -0.0339 & -0.0337 \\
\hline formal & 0.0033 & 0.0037 & -0.0069 & -0.0076 & -0.0074 & -0.0082 \\
\hline empregador & -0.0328 & -0.0325 & -0.0283 & -0.0281 & -0.0508 & -0.0504 \\
\hline indústria & 0.1007 & 0.1005 & -0.0594 & -0.0593 & 0.0700 & 0.0699 \\
\hline serviços & -0.0175 & -0.0175 & 0.0179 & 0.0179 & -0.0010 & -0.0010 \\
\hline urbano metropolitano & 0.0214 & 0.0219 & -0.0187 & -0.0191 & 0.0079 & 0.0081 \\
\hline urbano não metropolitano & -0.0007 & -0.0008 & -0.0004 & -0.0004 & -0.0015 & -0.0018 \\
\hline chefe de família & -0.0161 & -0.0197 & -0.0009 & -0.0011 & -0.0158 & -0.0193 \\
\hline \multicolumn{7}{|c|}{ Diferenças Considerando Coeficientes } \\
\hline escolaridade & 0.5299 & 0.4860 & -0.1154 & -0.0590 & -0.0102 & 0.0200 \\
\hline proxy experiêncial & 0.4532 & - & -0.3836 & - & 0.1266 & - \\
\hline proxy experiência 2 & - & 0.7829 & - & -0.3573 & - & 0.3495 \\
\hline filiação sindical & 0.0288 & 0.0283 & -0.0202 & -0.0201 & 0.0217 & 0.0213 \\
\hline formal & 0.0409 & 0.0375 & -0.0201 & -0.0222 & 0.0944 & 0.0921 \\
\hline empregador & 0.0077 & 0.0078 & 0.0097 & 0.0095 & -0.0026 & -0.0027 \\
\hline indústria & -1.0512 & -1.0632 & 0.0011 & 0.0015 & -0.8118 & -0.8206 \\
\hline serviços & -0.2667 & -0.2694 & 0.0180 & 0.0185 & -0.3079 & -0.3098 \\
\hline urbano metropolitano & 0.3696 & 0.3714 & -0.0485 & -0.0494 & 0.3463 & 0.3437 \\
\hline urbano não metropolitano & 0.0140 & 0.0142 & -0.0001 & -0.0011 & 0.0109 & 0.0100 \\
\hline chefe de família & 0.0253 & 0.0232 & 0.1776 & 0.1781 & -0.0013 & -0.0022 \\
\hline intercepto & -0.7876 & -1.0437 & 0.2464 & 0.1659 & -0.3852 & -0.6096 \\
\hline
\end{tabular}

Fonte: Cálculos pelos autores. 
Tabela 8 - Decomposição da Diferença de Rendimentos - 1996

\begin{tabular}{|c|c|c|c|c|c|c|c|c|c|}
\hline \multirow[b]{2}{*}{ Decoumosição } & \multicolumn{3}{|c|}{ Mulheres Brancas } & \multicolumn{3}{|c|}{ Homens Negros } & \multicolumn{3}{|c|}{ Mulheres Negras } \\
\hline & $\begin{array}{c}\text { proxy } \\
\text { experioncia } \\
1 \\
\end{array}$ & \begin{tabular}{|c|} 
proxy \\
experioncia \\
2 \\
\end{tabular} & \begin{tabular}{c|} 
proxy \\
exporiôncia \\
3 \\
\end{tabular} & $\begin{array}{c}\text { proxy } \\
\text { experiencia } \\
1 \\
\end{array}$ & \begin{tabular}{|c|} 
proxy \\
exporibincia \\
2 \\
\end{tabular} & $\begin{array}{c}\text { proxy } \\
\text { expriäncia } \\
3 \\
\end{array}$ & $\begin{array}{c}\text { proxy } \\
\text { exporiôncia } \\
1 \\
\end{array}$ & $\begin{array}{c}\text { proxy } \\
\text { experioncia } \\
2\end{array}$ & $\begin{array}{c}\text { proxy } \\
\text { expriáncia } \\
3 \\
\end{array}$ \\
\hline Caracteristicas & 0.1282 & 0.1394 & 0.1302 & -0.4130 & -0.4071 & -0.4106 & -0.3532 & -0.3364 & -0.3464 \\
\hline Coeficientes & -0.2011 & -0.2124 & -0.2031 & -0.0586 & -0.0645 & -0.0610 & -0.2700 & -0.2868 & -0.2768 \\
\hline \multicolumn{10}{|c|}{ Diferenças Considerando Características } \\
\hline escolaridade & 0.2926 & 0.2549 & 0.2230 & -0.3213 & -0.2844 & -0.2822 & -0.1117 & -0.1057 & -0.1137 \\
\hline $\begin{array}{l}\text { proxy } \\
\text { experiencial }\end{array}$ & -0.0592 & - & - & 0.0344 & - & - & 0.0045 & - & - \\
\hline $\begin{array}{l}\text { proxy } \\
\text { experiencia? }\end{array}$ & - & -0.0327 & - & - & 0.0050 & - & - & -0.0057 & - \\
\hline $\begin{array}{l}\text { proxy } \\
\text { experiencia3 }\end{array}$ & - & - & 0.0039 & - & - & -0.0053 & - & - & 0.0027 \\
\hline pormanencia & -0.0115 & -0.0168 & -0.0119 & -0.0068 & -0.0063 & -0.0059 & -0.0140 & -0.0190 & -0.0141 \\
\hline flicagdo sindical & -0.0018 & -0.0022 & -0.0020 & -0.0039 & -0.0047 & -0.0043 & -0.0089 & -0.0115 & -0.0098 \\
\hline formal & 0.0199 & 0.0212 & 0.0204 & -0.0139 & -0.0148 & -0.0143 & -0.0151 & -0.0161 & -0.0154 \\
\hline omprogador & -0.0304 & -0.0312 & -0.0303 & -0.0321 & -0.0329 & -0.0319 & -0.0575 & -0.0586 & -0.0571 \\
\hline indictria & 0.1088 & 0.1105 & 0.1073 & -0.0603 & -0.0612 & -0.0594 & 0.0898 & 0.0898 & 0.0886 \\
\hline serviços & -0.0365 & -0.0381 & -0.0365 & 0.0327 & 0.0341 & 0.0327 & -0.0256 & -0.0266 & -0.0256 \\
\hline $\begin{array}{l}\text { wrbana } \\
\text { motropolitana }\end{array}$ & 0.0477 & 0.0498 & 0.0476 & -0.0323 & -0.0338 & -0.0323 & -0.0080 & -0.0082 & -0.0079 \\
\hline $\begin{array}{l}\text { wroma ndo } \\
\text { motropolitana }\end{array}$ & -0.0004 & -0.0004 & -0.0005 & 0.0024 & 0.0024 & 0.0025 & 0.0102 & 0.0101 & 0.0105 \\
\hline chefe de famitia & -0.2083 & -0.1819 & -0.1971 & 0.0001 & 0.0001 & 0.0001 & -0.2080 & -0.1782 & -0.1969 \\
\hline male alfabotizada & 0.0074 & 0.0064 & 0.0062 & -0.0122 & -0.0106 & -0.0103 & -0.0089 & -0.0066 & -0.0075 \\
\hline \multicolumn{10}{|c|}{ Diferenças Considerando Coeficientes } \\
\hline escolaridade & 0.0698 & 0.0417 & 0.0553 & -0.1575 & -0.1413 & -0.1331 & -0.1566 & -0.1510 & -0.1228 \\
\hline $\begin{array}{l}\text { proxy } \\
\text { experiencial }\end{array}$ & 0.3785 & - & - & -0.3894 & - & - & -0.3668 & - & - \\
\hline $\begin{array}{l}\text { proxy } \\
\text { experiencia? }\end{array}$ & - & 0.4035 & - & - & -0.0986 & - & - & -0.1842 & - \\
\hline $\begin{array}{l}\text { proxy } \\
\text { experiencia3 }\end{array}$ & - & - & 0.1960 & - & - & -0.3198 & - & - & -0.5468 \\
\hline pomanéncia & -0.0463 & -0.0725 & -0.0431 & -0.0644 & -0.0933 & -0.0584 & -0.0720 & -0.0738 & -0.0690 \\
\hline fliagcho sindical & 0.0170 & 0.0135 & 0.0171 & 0.0050 & 0.0033 & 0.0042 & 0.0266 & 0.0254 & 0.0252 \\
\hline formal & -0.0476 & -0.0460 & -0.0384 & -0.0487 & -0.0509 & -0.0496 & -0.0397 & -0.0426 & -0.0413 \\
\hline omprogador & -0.0275 & -0.0294 & -0.0269 & -0.0101 & -0.0108 & -0.0103 & -0.0100 & -0.0093 & -0.0096 \\
\hline indietria & -0.2579 & -0.2907 & -0.3436 & 0.0650 & 0.0662 & 0.0699 & -0.5140 & -0.5329 & -0.5256 \\
\hline serviços & -0.0771 & -0.0859 & -0.0934 & 0.0264 & 0.0227 & 0.0273 & -0.1662 & -0.1757 & -0.1695 \\
\hline $\begin{array}{l}\text { wrbana } \\
\text { motropolitana }\end{array}$ & 0.1501 & 0.1609 & 0.1450 & -0.0683 & -0.0753 & -0.0696 & 0.1477 & 0.1500 & 0.1488 \\
\hline $\begin{array}{l}\text { wroma ndo } \\
\text { merropolitana }\end{array}$ & 0.0081 & 0.0151 & 0.0078 & -0.0225 & -0.0216 & -0.0240 & 0.0202 & 0.0236 & 0.0194 \\
\hline chepe de familia & -0.1023 & -0.0860 & -0.1057 & -0.3770 & -0.3394 & -0.3612 & -0.0645 & -0.0490 & -0.0598 \\
\hline mole alfabotizada & -0.0652 & -0.0652 & -0.0631 & 0.0071 & 0.0011 & 0.0017 & 0.0371 & 0.0265 & 0.0316 \\
\hline intercepto & -0.2007 & -0.1715 & 0.0899 & 0.9760 & 0.6736 & 0.8619 & 0.8881 & 0.7061 & 1.0426 \\
\hline
\end{tabular}

Fonte: Cálculos pelos autores. 
Tabela 9 - Decomposição da Diferença de Rendimentos - 2001-2007

Mullheres Brancas Homens Negros

\begin{tabular}{|c|c|c|c|c|c|c|c|c|c|}
\hline \multirow[b]{2}{*}{ Decomposiçào } & \multicolumn{3}{|c|}{ Mulheres Brancas } & \multicolumn{3}{|c|}{ Homens Negros } & \multicolumn{3}{|c|}{ Mulheres Negras } \\
\hline & $\begin{array}{c}\text { proxy } \\
\text { experiencia } \\
1\end{array}$ & $\begin{array}{c}\text { proxy } \\
\text { experiência } \\
2\end{array}$ & \begin{tabular}{|c|} 
proxy \\
experiencia \\
3
\end{tabular} & $\begin{array}{c}\text { proxy } \\
\text { experiência } \\
1\end{array}$ & $\begin{array}{c}\text { proxy } \\
\text { experiência } \\
2\end{array}$ & $\begin{array}{c}\text { proxy } \\
\text { experiência } \\
3\end{array}$ & $\begin{array}{c}\text { proxy } \\
\text { oxperiência } \\
1\end{array}$ & \begin{tabular}{|c|} 
proxy \\
experiência \\
2
\end{tabular} & $\begin{array}{c}\text { proxy } \\
\text { experiência } \\
3\end{array}$ \\
\hline Caracteristicas & 0.2689 & 0.2346 & 0.2651 & -0.2406 & -0.2370 & -0.2392 & 0.0158 & -0.0041 & 0.0101 \\
\hline Coeficientes & -0.2903 & -0.2560 & -0.2865 & -0.0423 & -0.0458 & -0.0437 & -0.4186 & -0.3988 & -0.4129 \\
\hline \multicolumn{10}{|c|}{ Diferenças Considerando Características } \\
\hline escolaridade & 0.2525 & 0.1864 & 0.0811 & -0.1997 & -0.1366 & -0.0594 & 0.0303 & 0.0190 & 0.0090 \\
\hline $\begin{array}{l}\text { proxy } \\
\text { experiêncial }\end{array}$ & -0.0521 & - & - & 0.0538 & - & - & -0.0510 & - & - \\
\hline $\begin{array}{l}\text { proxy } \\
\text { experiência2 }\end{array}$ & - & -0.0594 & - & - & 0.0067 & - & - & -0.0300 & - \\
\hline $\begin{array}{l}\text { proxy } \\
\text { experiência } 3\end{array}$ & - & - & -0.0171 & - & - & -0.0083 & - & - & -0.0213 \\
\hline permanéncia & -0.0071 & -0.0352 & -0.0276 & 0.0009 & 0.0010 & 0.0008 & -0.0344 & -0.0389 & -0.0320 \\
\hline filiação sindical & -0.0021 & -0.0025 & -0.0023 & -0.0016 & -0.0019 & -0.0017 & -0.0044 & -0.0052 & -0.0047 \\
\hline formal & 0.0190 & 0.0197 & 0.0191 & -0.0148 & -0.0154 & -0.0149 & -0.0117 & -0.0120 & -0.0117 \\
\hline ompregador & -0.0281 & -0.0286 & -0.0279 & -0.0234 & -0.0238 & -0.0232 & -0.0365 & -0.0371 & -0.0363 \\
\hline induistria & 0.1213 & 0.1244 & 0.1210 & -0.0680 & -0.0697 & -0.0678 & 0.0959 & 0.0972 & 0.0957 \\
\hline senviços & -0.0150 & -0.0151 & -0.0149 & 0.0340 & 0.0342 & 0.0338 & 0.0017 & 0.0016 & 0.0016 \\
\hline $\begin{array}{l}\text { urbana } \\
\text { metropolitana }\end{array}$ & 0.0266 & 0.0314 & 0.0266 & -0.0100 & -0.0119 & -0.0100 & 0.0136 & 0.0152 & 0.0137 \\
\hline $\begin{array}{l}\text { urbana não } \\
\text { metropolitana }\end{array}$ & -0.0005 & -0.0008 & -0.0006 & 0.0000 & -0.0001 & -0.0001 & -0.0002 & -0.0002 & -0.0002 \\
\hline chefe de familia & -0.0455 & -0.0567 & -0.0451 & 0.0001 & 0.0002 & 0.0001 & -0.0433 & -0.0524 & -0.0429 \\
\hline \multicolumn{10}{|c|}{ Diferenças Considerando Coeficientes } \\
\hline escolaridade & 0.1841 & 0.3316 & 0.5940 & -0.2243 & -0.1977 & -0.1476 & 0.0366 & -0.0309 & 0.2436 \\
\hline $\begin{array}{l}\text { proxy } \\
\text { experiéncial }\end{array}$ & 0.1856 & - & - & -0.2437 & - & - & 0.1092 & - & - \\
\hline $\begin{array}{l}\text { proxy } \\
\text { expeniência2 }\end{array}$ & - & 0.2009 & - & - & -0.1318 & - & - & -0.0312 & - \\
\hline $\begin{array}{l}\text { proxy } \\
\text { expenîncia } 3\end{array}$ & - & - & 0.7378 & - & - & -0.0893 & - & - & 0.5829 \\
\hline permanência & -0.0026 & 0.0394 & 0.0336 & -0.0201 & -0.0302 & -0.0130 & -0.0325 & -0.0308 & -0.0276 \\
\hline filiação sindical & 0.0079 & 0.0077 & 0.0069 & -0.0002 & -0.0010 & -0.0009 & 0.0012 & 0.0007 & 0.0004 \\
\hline formal & 0.0358 & 0.0376 & 0.0392 & 0.0124 & 0.0128 & 0.0128 & 0.0662 & 0.0716 & 0.0684 \\
\hline empregador & 0.0018 & 0.0021 & 0.0017 & -0.0008 & -0.0010 & -0.0010 & 0.0026 & 0.0027 & 0.0026 \\
\hline indistria & -0.4522 & -0.4841 & -0.4779 & -0.0454 & -0.0476 & -0.0454 & -0.5059 & -0.5221 & -0.5137 \\
\hline senviços & -0.1930 & -0.2028 & -0.2009 & -0.0307 & -0.0300 & -0.0291 & -0.2556 & -0.2613 & -0.2584 \\
\hline $\begin{array}{l}\text { urbana } \\
\text { metropolitana }\end{array}$ & 0.2523 & 0.2534 & 0.2491 & -0.0513 & -0.0588 & -0.0519 & 0.2548 & 0.2573 & 0.2524 \\
\hline $\begin{array}{l}\text { urbana não } \\
\text { metropolitana }\end{array}$ & 0.0395 & 0.0425 & 0.0387 & -0.0165 & -0.0176 & -0.0171 & 0.0526 & 0.0540 & 0.0518 \\
\hline chefe de familia & -0.0279 & -0.0297 & -0.0288 & -0.0160 & -0.0229 & -0.0154 & -0.0233 & -0.0278 & -0.0242 \\
\hline intercepto & -0.3214 & -0.1991 & -0.5823 & 0.5018 & 0.4117 & 0.3530 & 0.0171 & 0.1589 & -0.3011 \\
\hline
\end{tabular}

Fonte: Cálculos pelos autores. 